ANUARIo DE Estudios MEDIEVALES 48/2, julio-diciembre de 2018, pp. 925-953

ISSN 0066-5061

https://doi.org/10.3989/aem.2018.48.2.14

\title{
DEUTE PÚBLIC I RENDA CENSALISTA AL PAÍS VALENCIÀ EN EL SEGLE XV. UNA PROPOSTA D’INTERPRETACIÓ
}

\author{
PUBLIC DEBT AND PERPETUAL ANNUITIES IN FIFTEENTH-CENTURY \\ VALENCIA. A PROPOSAL FOR AN INTERPRETATION
}

\author{
PAU VICIANO \\ Universitat de València \\ http://orcid.org/0000-0002-7190-0001
}

\begin{abstract}
Resum: L'emergència de la nova fiscalitat -de la Corona, de les ciutats i del regne- va ser, sens dubte, una de les grans transformacions polítiques i econòmiques del final de l'edat mitjana. Amb l'impost va aparèixer un deute públic consolidat que, en la Corona d'Aragó, es va desenvolupar mitjançant el censal, un instrument financer semblant a les rentes constituées franceses o les perpetual annuities angleses. A partir del cas del País Valencià, pot assajar-se una estimació del volum de rendes generat pel deute públic i de com es distribuïen des del punt de vista geogràfic i social. Així doncs, en aquest article s'estudia en quins nivells de la xarxa urbana es concentraven aquests recursos i quins grups socials eren els seus principals beneficiaris, amb especial atenció a la noblesa, que va trobar en aquesta forma d'ingressos un complement al declivi o a la insuficiència de la renda feudal en una època de reestructuració de la societat.
\end{abstract}

Paraules clau: deute públic; censals; renda feudal; fiscalitat; noblesa; Corona d'Aragó; edat mitjana.

Abstract: The emergence of the new taxation -of the Crown, the cities and the kingdom- was undoubtedly one of the main political and economic transformations of the late Middle Ages. With taxes a consolidated public debt appeared, which in the Crown of Aragon developed by means of censals, a financial instrument similar to the French rentes constituées or English perpetual annuities. On the basis of the case of Valencia, an attempt can be made to estimate the amount of income generated by public debt in the region and how it was distributed from the geographical and social perspective. Thus, this article studies at what levels of the urban network these resources were concentrated and which social groups were their main beneficiaries, with special attention being paid to the nobility, who found in this form of income a supplement to declining or insufficient feudal rents at a time of social restructuring.

Keywords: public debt; perpetual annuities; feudal rents; taxation; nobility; Crown of Aragon; Middle Ages.

\section{SUMARI}

1. Una aproximació a les magnituds del deute públic censalista.- 2. Els beneficiaris de les rendes: territoris i sectors socials.- 3. Estratègies rendistes.- 4. Renda censalista i transformacions socials.- 5. Bibliografia citada.

Cómo citar este artículo: Viciano, Pau (2018), Deute públic i renda censalista al país Valencià en el segle XV. Una proposta d'interpretació, "Anuario de Estudios Medievales" 48/2, pp. 925-953. https://doi.org/10.3989/aem.2018.48.2.14

Copyright: (c) 2018 CSIC. This is an open-access article distributed under the terms of the Creative Commons Attribution 4.0 International (CC BY 4.0) License. 
L'emergència dels nous sistemes fiscals vinculats al poder estatal o reial va ser, sens dubte, una de les transformacions polítiques i econòmiques que van marcar el final de l'edat mitjana ${ }^{1}$. L'impost no sols era una càrrega més que s'afegia a les tradicionals exaccions senyorials, sinó també un poderós mecanisme de transferència de rendes cap als sectors dominants, fonamentalment nobiliaris, que a través dels oficis burocràtics o de la guerra es van posar al servei de l'Estat. L'anomenada "renda feudal centralitzada", malgrat la seua aparença contradictòria, descrivia la funció de l'impost com a nova font d'ingressos per a una noblesa que ja no podia viure exclusivament de les seues senyories. El cas de la Corona d'Aragó, l'anomenat "pactisme", més enllà de configurar-ne l'arquitectura constitucional i unes noves identitats polítiques de base territorial, tenia aquesta altra cara: la de l'impost i, amb ell, el deute públic. La recaptació dels serveis aprovats en les Corts, sobretot des de l'últim terç del segle XIV, repercutia en un endeutament dels municipis, majoritàriament a través de les emissions de censals, que només va poder afrontar-se amb la creació d'una nova fiscalitat local basada en l'impost indirecte sota la forma de cises o imposicions. Paral-lelament, les Diputacions permanents de les Corts es van dotar d'una fiscalitat pròpia, les anomenades generalitats, també de tipus indirecte, per reunir part dels serveis atorgats al monarca per aquestes assemblees estamentals ${ }^{2}$. Ara bé, l'agilitació d'aquests pagaments també exigia recórrer a l'endeutament censalista, de forma semblant a les hisendes municipals. D'aquesta manera, l'entramat pactista generava unes enormes demandes fiscals que es traduïen en una veritable espiral del deute a llarg termini -municipal i de les Diputacions de les Corts- a través dels censals. A part del negoci especulatiu de l'arrendament dels diferents impostos, els interessos del deute públic representaven un gran volum de renda que es repartia entre els inversors privats.

A partir del cas del País Valencià, pot assajar-se una estimació del volum de rendes generat pel deute públic i de com es distribuïa des del punt de vista geogràfic i social, és a dir, en quins nivells de la xarxa urbana es concentraven aquests recursos i quins grups socials eren els seus principals beneficiaris, amb especial atenció a la noblesa, que va trobar en aquesta forma de renda una alternativa -o millor, un complement-al declivi o la insuficiència

${ }^{1}$ Fins i tot centrant-nos només en la Corona d'Aragó, en el seu context peninsular i europeu, la bibliografia resulta ja tan abundant que només podem esmentar ara, pel seu caràcter col-lectiu, obres com les editades per Sánchez Martínez 1999, 2009; Sánchez Martínez, Menjot 1996-2005 (4 vols.), 2006; Sánchez Martínez, Furió 1997; Menjot, Rigaudière, Sánchez Martínez 2005.

${ }^{2}$ Aquestes Diputacions, que aviat serien conegudes com a Generalitats, estaven formades per delegats dels braços representats a les Corts, en el cas valencià el reial, l'eclesiàstic i el militar. Sobre l'origen d'aquesta institució, Muñoz 1987. 
dels ingressos de les seues senyories. Però l'abast del rendisme censalista encara va tenir altres implicacions que l'inserien en l'engranatge de les grans transformacions polítiques i socials de la fi de l'edat mitjana. Des d'un punt de vista territorial, aquest flux de rendes reafirmava l'hegemonia de la ciutat de València sobre les altres poblacions del regne. Políticament, la dependència que creava l'endeutament municipal reforçava el poder autoritari del monarca sobre les ciutats i viles reials, mentre que, des d'una perspectiva social, les pensions censalistes s'equiparaven a les rendes senyorials ${ }^{3}$ i facilitaven així els processos d'aristocratització dels estrats superiors de la burgesia ${ }^{4}$ i la seua fusió amb la vella noblesa. Evidentment, aquestes transformacions comunes a tota l'Europa que es reorganitzava després de la crisi baixmedieval no van ser causades per l'impacte del deute censalista, però la forma concreta en què es van manifestar a la corona catalanoaragonesa, i concretament al País Valencià, no podria entendre's sense l'enorme massa de renda que el deute públic va permetre d'assignar als sectors dominants d'una societat feudal en plena reestructuració.

\section{UNA APROXIMACIÓ A LES MAGNITUDS DEL DEUTE PÚBLIC CENSALISTA}

La ciutat de València va ser, sens dubte, la peça central del deute públic en el conjunt del País Valencià ${ }^{5}$. Per valorar la importància del volum total de la renda que redistribuïa la ciutat als seus creditors censalistes, cal considerar que aquesta suma era comparable a la d'altres magnituds fiscals relatives al conjunt del regne ${ }^{6}$. En 1415 València pagava, 545.000

\footnotetext{
${ }^{3}$ Evidentment, la renda de la senyoria -la renda feudal pròpiament dita-tenia una naturalesa ben diferent de la renda censalista, ja que en aquest darrer cas el lligam entre el perceptor i el pagador era de naturalesa econòmica i no social com el vincle senyorial. A més, la renda censalista era redimible pel deutor i negociable en el mercat pel creditor. L'assimilació es donava en tant que la renda censalista era un ingrés regular i socialment honorable.

${ }^{4}$ Fem servir el terme "burgesia" o "burgesos" com una denominació merament pràctica per a referir-nos, de manera agrupada, a mercaders, ciutadans rendistes i professionals liberals. En aquest sentit no era una denominació estranya a l'edat mitjana, encara que en l'àmbit català solia denominar-se "mà mitjana", com feia el tractadista Francesc Eiximenis, que hi agrupava els "juristes, notaris, mercaders e drapers poderosos, e tots aquells qui sens generositat notable han grans riquees en la ciutat", citat per Rubio 2003, p. 31 .

${ }^{5}$ Sobre el deute públic municipal disposem de les síntesis de Furió 2002, 2005. Per a la Corona d'Aragó en el context europeu, des d'una perspectiva sociopolítica, poden veure's els articles aplegats a Boone, Davids, Janssens 2003. Amb un interès més centrat en l'estructuració econòmica del mercat del deute, Zuijderduijn 2009.

${ }^{6}$ Les comparacions amb les recaptacions fiscals permeten avaluar el gran l'impacte del deute públic dins de l'entramat financer i hisendístic, cosa que no significa que el seu relleu pogués relativitzar-se en comparació amb altres sectors de l'activitat econòmica, com ara els negocis de les grans companyies mercantils.
} 
sous en pensions ${ }^{7}$, mentre que els ingressos de la Generalitat -basats en la nova fiscalitat d'Estat- se situaven en 430.000 sous en el mateix any ${ }^{8}$. Les rendes ordinàries de la batllia general del regne de València, és a dir, del domini patrimonial de la Corona, en 1412 assolien uns 500.000 sous $^{9}$. Finalment, els donatius concedits per les Corts suposaven, en aquells anys, una mitjana anual de 143.000 sous per a les arques reials ${ }^{10}$. Per tant, el pes dels interessos del deute públic de la ciutat de València equivalia a les rendes ordinàries del conjunt del patrimoni reial i era major que els ingressos de la gran institució de la nova fiscalitat estamental -la Diputació del General o Generalitat- i, més clarament encara, superava els subsidis que les Corts assignaven directament a les poblacions del regne. Mig milió de sous era, en un altre ordre de comparacions, l'equivalent a 33.000 hectolitres de blat -el consum anual de 8.000 persones $-{ }^{11} \mathrm{o}$ la renda feudal que produïen cinquanta senyories de les dimensions de Catarroja o Torrent, poblacions d'un centenar de vassalls cristians ${ }^{12}$.

Al deute de la capital se sumava el de la resta de poblacions del regne, des de les ciutats situades en el rang immediatament inferior a la gran urbs valenciana fins a les comunitats estrictament rurals, ja que tots aquests nuclis demogràfics s'havien constituït com a municipis segons el model de la capital i es van veure sotmesos a necessitats de crèdit, salvades les proporcions, de caràcter semblant. Si es té en compte que el factor que va iniciar l'escalada del deute censalista van ser sobretot els subsidis aprovats en les Corts i altres despeses vinculades a les demandes extraordinàries de la Corona, s'explica que els municipis senyorials i eclesiàstics es veiessen carregats amb un deute censalista de pes semblant al del domini reial ${ }^{13}$.

\footnotetext{
${ }^{7}$ Belenguer 1976, pp. 58-59. Sobre els orígens del mercat del deute a València, $c f$. García Marsilla 2002.

${ }^{8}$ Així es desprèn de les dades que aporta Muñoz 1987.

${ }^{9}$ Guinot 1992, p. 631.

${ }^{10}$ Calculat a partir de les informacions de Muñoz 1987.

${ }^{11}$ Considerant que un cafís de forment $(2 \mathrm{hl}$ ) valia 30 sous i que una persona en consumia dos a l'any, segons Furió 1997, p. 520.

${ }^{12}$ Febrer 1984; Viciano 1989, pp. 106-108.

${ }^{13}$ Les causes del deute públic no es limitaven a aquestes demandes fiscals, ja que d'altres necessitats, com l'abastament frumentari en èpoques de males collites, tingueren una incidència remarcable, però l'escalada que es constata des de mitjan segle XIV obeïa sobretot a la pressió de la fiscalitat extraordinària, al capdavall, com a tot Europa, lligada a la guerra.
} 
Quadre 1. Pensions censalistes pagades per les poblacions valencianes ${ }^{14}$

\begin{tabular}{|c|c|c|c|c|c|c|}
\hline & & PENSIONS & $\begin{array}{c}\text { \% DESPESA } \\
\text { MUNICIPAL }\end{array}$ & $\begin{array}{c}\text { \% CREDITORS } \\
\text { DE VALÈNCIA }\end{array}$ & FOCS & SOUS/FOC \\
\hline 1362 & Vila-real & 14.000 & 44 & 65 & $590^{\mathrm{a}}$ & 24 \\
\hline 1372 & Vilafamés & 4.600 & & 22 & $200^{\mathrm{b}}$ & 23 \\
\hline 1380 & Alzira & 49.000 & 71 & 61 & $1.652^{\mathrm{c}}$ & 30 \\
\hline 1426 & Alcoi & 10.700 & 66 & & $260^{\mathrm{d}}$ & 41 \\
\hline 1426 & Castelló & 37.600 & 51 & 77 & $883^{\mathrm{e}}$ & 42 \\
\hline 1444 & Sueca & 10.000 & 72 & 50 & $183^{\mathrm{f}}$ & 54 \\
\hline 1449 & Borriana & 9.500 & 25 & 75 & $264^{\mathrm{g}}$ & 36 \\
\hline 1459 & Onda & 31.500 & & 81 & $397^{\mathrm{h}}$ & 79 \\
\hline 1473 & Alcoi & 3.700 & & & $346^{\mathrm{i}}$ & 10 \\
\hline 1486 & Gandia & 25.200 & 66 & 75 & $363^{\mathrm{j}}$ & 69 \\
\hline 1499 & Castelló & 30.000 & & & 484 & 62 \\
\hline 1501 & Castalla & 2.500 & & 65 & $114^{\mathrm{k}}$ & 22 \\
\hline
\end{tabular}

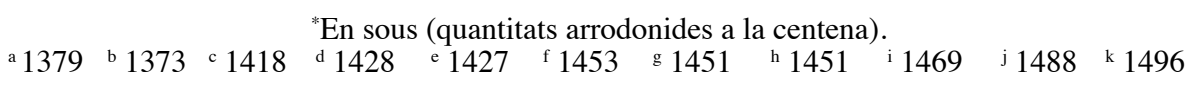

Les dades disponibles sobre el deute censalista de les ciutats i viles del regne, doncs, estan lluny de ser tan exhaustives com les de València, però permeten assajar una estimació global del volum de pensions que satisfeien en el primer terç i a la fi del segle XV. Sabem que en 1427 la població del braç reial, sense incloure la ciutat de València, tenia 14.668 focs segons l'impost del monedatge (morabatí). Ara bé, pot establir-se una càrrega mitjana de pensions per foc? Les dades, com hem dit, són escasses: entre la fi del segle XIV $i$ els anys quaranta del XV, aquestes mitjanes oscillaven entre els 30 i els 54 sous per foc, amb uns 40 per als dos casos -Alcoi i Castelló- datats en 1426 (quadre 1). Si es prenia aquest mòdul de 40 sous, cosa que sembla una estimació prudent, el conjunt de les rendes censalistes podria haver-se situat en uns 580.000 sous, una suma semblant als 564.000 sous que, efectivament, pagava en 1430 la capital del regne als seus censalistes ${ }^{15}$. Aquesta estimació es veu reforçada si es considera que, en aquests anys, les càrregues fiscals que les Corts imposaven en forma de compartiments, en el cas del braç reial, es dividien a parts iguals entre la ciutat de València i la resta de municipis. Per la

${ }^{14}$ Font: elaboració pròpia a partir de les dades aportades per Fradejas y García 1989; Furió 1993, 1997, 1999; Furió i Garcia 1985; Mira 1997, 2005; Pastor 1992; Olaso 1987; Del Pozo 1995; Rabassa i Díaz de Rábago 1995; Valldecabres 2002; Viciano 1990, 1992, 2008.

${ }^{15}$ Belenguer 1976, pp. 58-59 
seua banda, en 1430 el braç nobiliari agrupava un total de 16.958 focs $^{16}$. Cal dir que la majoria d'aquesta població estava formada per vassalls musulmans -un $60 \%$ a l'inici del segle $\mathrm{XVI}^{17}$ - que s'enquadraven en aljames amb una estructura política i fiscal diferent de la dels municipis de veïns cristians. Ara bé, tot indica que aquestes aljames es trobaven més endeutades encara que la resta de poblacions del país, tot i que de vegades no resulta evident si els censals eren carregats per les comunitats camperoles o pels seus senyors ${ }^{18}$. Així doncs, no existeixen raons significatives per renunciar a aplicar-hi el mateix mòdul de 40 sous per foc, de manera que el volum de les pensions pagades per les comunitats senyorials podria situar-se en uns 680.000 sous. En el cas de les poblacions de senyoria eclesiàstica, entre les quals els ordes militars com el de Montesa tenien un pes determinant, pot considerar-se que la càrrega de pensions per foc seria similar a la dels municipis reials, però se'n desconeix el nombre exacte de vassalls. En una estimació regressiva a partir del cens de 1510 i dels fogatges de Montesa, pot considerar-se que cap a 1430 les possessions de l'Església reunirien uns 8.500 focs $^{19}$. Una vegada més, si s'aplicava el mòdul de 40 sous per foc, les poblacions eclesiàstiques pagarien en conjunt uns 340.000 sous de pensions. D'aquesta manera, al més de mig milió de sous que satisfeia la ciutat de València als seus censalistes, caldria afegir les sumes pagades per la resta de poblacions del regne, que -en una primera aproximació - podrien acostar-se a 1,6 milions més de sous. Així doncs, podria admetre's com una hipòtesi versemblant que els interessos del deute públic municipal de tot el País Valencià podien superar, en el primer terç del segler $\mathrm{XV}$, els dos milions de sous.

Aquesta enorme massa de diners no va fer més que incrementar-se al llarg del segle. En 1493 la població del braç reial, exceptuant la ciutat de València, segons les dades del morabatí assolia els 12.187 focs, mentre que el recompte del braç militar, en 1488, donava una xifra de 22.778 focs $^{20}$. Per la seua banda, les poblacions de titularitat eclesiàstica devien situar-se al voltant dels 6.000 focs, de manera que el volum demogràfic del regne, tret de la capital, a la fi del segle XV podria estar al voltant dels 41.000 focs. Ara bé, la disparitat de les càrregues censalistes que suportaven les poblacions valencianes -molt més reduïda a les comarques meridionals - aconsella establir dos mòduls

\footnotetext{
${ }^{16}$ Les dades demogràfiques de 1427 i 1430 en López 2005, pp. 90 i 100.

${ }^{17}$ Viciano 2012, p. 55.

${ }^{18}$ En qualsevol cas, acabaven pesant sobre els vassalls, $c f$. Pastor 1984; Garcia-Oliver 1997.

${ }^{19}$ L'estimació (Viciano, en premsa) es basa sobretot en els vassalls eclesiàstics del nord del regne, que sumaven 6.962 focs en 1427 i 4.212 en 1493, segons pot comptabilitzar-se a partir de les dades de Guinot 1988.

${ }^{20} C f$. López 2005, p. 90.
} 
diferents: uns 15 sous de pensions per foc en el sud -la mitjana d'Alcoi i Castalla - i 60 sous per a la resta del territori (quadre 1). D'aquesta manera, pot estimar-se que els més de 9.000 focs que en conjunt representaven les poblacions meridionals ${ }^{21}$ pagarien més de 130.000 sous, mentre que els 32.000 focs restants s'aproparien als dos milions de sous. Aquestes sumes estimades, unides als 757.000 sous que sabem documentalment que satisfeia la ciutat de València als seus censalistes ${ }^{22}$, permeten suposar que a la fi del segle XV els municipis del regne generaven unes rendes que podien situar-se en més de 2,8 milions de sous ${ }^{23}$.

Almenys durant el segle XV, les finances de la Generalitat no van generar un volum de deute -i de pensions- comparable al dels municipis. Al principi, la funció de la Diputació permanent era recaptar els impostos -mitjançant compartiments i generalitats- que eren aprovats en les Corts, però la necessitat d'anticipar el producte de les recaptacions provocava que aquesta institució hagués de recórrer al mercat censalista per aconseguir préstecs amb els quals satisfer al monarca les contribucions estamentals. En bona mesura, les recaptacions efectives dels impostos no anaven tant a les arques reials com a satisfer els interessos del deute que s'havia generat. Ara bé, durant el primer quart del segle $\mathrm{XV}$, aquests recursos financers no van provocar una espiral censalista, ja que en cicles de set o deu anys s'aconseguia sanejar el deute públic fins que es feia necessària una nova emissió ${ }^{24}$. Sabem que en 1418 es van carregar censals per un muntant global de 2,2 milions de sous, que a un interès habitual del 7,14\%, suposarien unes pensions d'uns 160.000 sous $^{25}$. Ara bé, considerant que hi hauria d'altres censals vigents, pot pensar-se que les rendes que la Generalitat pagaria als seus creditors censalistes en aquests anys s'acostarien, més aviat, als 200.000 sous $^{26}$, una suma ja considerable que

${ }^{21}$ Es tracta de les poblacions pertanyents a les actuals comarques de la Marina, el Comtat, l'Alcoià i l'Alt Vinalopó i al sud d'aquest límit. En 1488 les poblacions meridionals del braç nobiliari superaven els 6.000 focs (segons les dades de Valldecabres 2002, pp. 548-558), les viles reials n'asssolien quasi 3.000 en 1493 (Furió 1995, p. 186) i les eclesiàstiques -ja per a 1510- en tenien uns 200 (Valldecabres 2002, pp. 29-31).

${ }^{22}$ Belenguer 1976, pp. 58-59.

${ }^{23}$ La versemblança d'aquestes estimacions es veu reforçada pels càlculs efectuats per Antoni Furió en una recerca paral-lela, publicada quan aquest article es trobava en premsa. A partir d'aproximacions diferents a les nostres, com ara detallant l'anàlisi per rangs de població, aquest autor estima que el volum de les pensions censalistes dels municipis del regne, al llindar del segle XVI, se situaria entre 2,87 i 3 milions de sous (Furió 2018).

${ }^{24}$ Muñoz 1987.

${ }^{25}$ Calculat amb la informació que aporta López 2005, pp. 379-384.

${ }^{26}$ Entre 1418 i 1424 es van carregar censals per un capital global de 4,3 milions de sous (segons càlculs propis a partir de les dades de López 2005, p. 379), que reportarien uns 300.000 sous de pensions, però el més probable és que tots aquests carregaments no s'haguessen acumulat sinó que una part devia servir per quitar-ne d'altres, de manera que el volum real de pensions 
va incrementar-se acceleradament al llarg del segle $\mathrm{XV}$, fins arribar a més de 400.000 sous als anys vuitanta ${ }^{27}$.

Amb la cautela que les úniques xifres realment documentades són les corresponents a la ciutat de València, pot estimar-se, ni que siga a grans trets, que cap a 1430 els interessos del deute públic censalista de les principals institucions del regne podrien superar els dos milions de sous ${ }^{28}$, que equivaldrien a més de 4.200 kilograms de plata fina ${ }^{29}$. Es tractava d'una magnitud que duplicava el volum conjunt de les rendes ordinàries del domini reial i de la nova fiscalitat d'Estat. Equivalia, així mateix, a la renda que podia obtenir-se de dues-centes senyories de dimensions mitjanes, d'entre un i dos centenars de focs cristians. ${ }^{30}$ I era també el valor de 133.000 hectolitres de blat, suficients per alimentar durant un any 33.000 persones. Aquest enorme volum de les rendes censalistes encara s'incrementaria al llarg del Quatrecents, fins al punt que cap a 1490 podia superar amb escreix els tres milions de sous. Es tractaria, una vegada més, d'una magnitud segurament molt superior a la de les principals recaptacions fiscals i equivalent a la renda de tres-centes senyories mitjanes o al consum cerealista de 50.000 persones, és a dir, al proveïment frumentari anual de la ciutat de València.

\section{ELS BENEFICIARIS DE LES RENDES: TERRITORIS I SECTORS SOCIALS}

A grans trets, el mercat del deute censalista del regne de València estava unificat per l'hegemonia de la gran urbs com a centre financer, on es concentraven els ciutadans i aristòcrates, però també nombroses institucions -començant per les religioses-, que disposaven de capitals líquids per invertir en la compra de rendes censalistes. Els creditors de València, doncs, percebien pensions de municipis dispersos per tot el regne, encara que la seua influència es difuminava a les zones frontereres del nord i sobretot del sud. La diferent presència de creditors de la capital, no obstant això, no depenia tant de la

pagat simultàniament seria inferior, potser a l'entorn dels 200.000 sous, és a dir, semblant a les pensions dels carregaments de 1418 .

${ }^{27}$ En 1483 les pensions pagades per la Generalitat ascendien a 414.000 sous (Furió 2018, p. 127).

${ }^{28}$ La batllia general del regne de València també es va veure implicada en el pagament de deute censalista, però a una escala molt inferior, al voltant d'uns 100.000 sous al llarg del segle XV (Vegeu López 1994; Furió 2018, p. 128).

${ }^{29}$ Suposant que les pensions es pagassen en moneda de plata, que era el reial o divuitè, equivalent a 18 diners menuts. Des de 1423 el pes aproximat de plata en cada moneda era de 3,16 grams, així que un sou en tindria 2,106 (agraïm aquestes dades a l'amabilitat de Josep Torró).

${ }^{30}$ Vegeu el quadre 3. 
major o menor distància geogràtica com de la presència de censalistes locals capaços d'invertir en el deute públic dels seus propis municipis. Així mateix, l'existència de ciutats i viles que exercien com a capitals comarcals, on podien trobar-se les sumes que necessitaven els llocs i alqueries del seu entorn rural, podia fer innecessari acudir al mercat financer de València, limitant així la penetració dels seus censalistes. En general, la necessitat de buscar finançament fora de la pròpia localitat era més apressant en les poblacions més petites, sovint comunitats rurals, on no existien veïns acomodats capaços d'invertir en el deute públic local. De les pensions que pagava Cullera entre 1390 i 1500, només un $4 \%$ beneficiava a inversors locals, mentre que el $90 \%$ corresponia a rendistes de la ciutat de València ${ }^{31}$. Ara bé, la dependència del mercat financer centrat a la capital del regne també era una realitat inevitable per a poblacions de majors dimensions, fins i tot ciutats i viles de trets urbans. La diferència era que aquests municipis -com Vila-real, Castelló, Borriana o Onda, per no sortir de la Plana- podien obtenir una part -sempre minoritària- del seu finançament entre els propis veïns i en altres poblacions que, en certa manera, tendien a exercir com a capitals comarcals (quadre 1). Es delimitaven així dos tipus de circuits financers: uns de nivell local i comarcal, basats en les viles i llocs de trets urbans, i un altre d'abast regional, al llarg de tot el regne, que tenia el seu centre a la ciutat de València i se superposava als primers cobrint també els seus intersticis. La diferència fonamental entre aquests segments del mercat censalista estava en el volum dels capitals i de les pensions corresponents. Així doncs, aquests dos circuits no eren excloents sinó que una mateixa localitat es veia immersa en tots dos, i en el cas de poblacions d'una certa entitat se situaven simultàniament en el costat de l'oferta i de la demanda de crèdit. Una vila com Castelló havia de recórrer al mercat financer de València per endeutar-se, però ella mateixa era una plaça secundària on trobar capitals, tant per invertir en el deute públic local com en altres poblacions properes de menor rang urbà. Així, al segle XV els censalistes de Castelló cobraven pensions de municipis de la mateixa comarca de la Plana i d'altres veïnes com l'Alt Palància, el Alcalatén o el Baix Maestrat ${ }^{32}$. Aquest radi geogràfic local i comarcal coincidia amb el del mercat del crèdit privat, ja que els pagesos que necessitaven préstecs per valor d'uns centenars de sous trobaven els capitals, sense haver d'acudir a València, en la seua localitat o en una vila propera.

Amb tota seguretat, el saldo entre les pensions censalistes que pagava una vila com Castelló i les que cobraven els seus propis veïns d'altres

${ }^{31}$ Furió 1993, p. 520.

32 Viciano 2008, p. 213. Per altra banda, la comptabilitat municipal de viles com Borriana, Onda i Vila-real indica que aquestes poblacions de la Plana també pagaven censals a veïns de Castelló. 
municipis era negatiu, ja que el deute amb els creditors de València era d'un volum tal que difícilment seria comparable als capitals invertits fora pels censalistes locals. D'aquesta manera, pot dir-se que, si bé coexistien diversos circuits financers, es trobaven clarament jerarquitzats en benefici de la capital del regne, que era la gran plaça financera regional. En qualsevol cas, en l'estat actual de les recerques, no és possible intentar una estimació, per aproximada que fos, al flux de rendes censalistes que circulava per aquests circuits comarcals. Es tractava d'uns segments del mercat financer molt atomitzats i no sempre clarament enquadrats per les viles i ciutats petites, ja que trobem llocs menors on residien censalistes que havien invertit en el deute de poblacions més urbanes. Amb tot, en trets generals, el model financer que sembla esbossar-se tendia a reproduir les jerarquies urbanes: les poblacions rurals pagaven pensions a les viles i ciutats, i aquestes a la capital valenciana, que la seua vegada també absorbia rendes procedents directament del nivell inferior, de llocs i comunitats rurals de tot el País Valencià. Són aquestes transferències cap al gran centre financer les que poden estimarse a partir de les comptabilitats municipals. La proporció del deute públic en mans de censalistes de València (quadre 1) oscil-lava entre $22 \%$ del total de les pensions documentat per a Vilafamés a la fi del segle XIV i el $90 \%$ corresponent a Cullera en 1390-1500. Entre aquests valors extrems, amb un 50-60\% se situaven els casos de Sueca, Alzira, Vila-real i Castalla (65\%), i ja per damunt del 75\% Borriana, Gandia, Castelló, Onda i Alcoi. Pot estimar-se, així, que en termes mitjans, les rendes censalistes que els municipis de tot el país pagaven a creditors de València se situaria entorn de dos terços del total. Les escasses dades relatives a les alqueries musulmanes no qüestionen el predomini dels censalistes de València, sinó que -és el cas del Real, en l'horta de Gandia- fins i tot suggereixen una hegemonia encara major ${ }^{33}$. D'aquesta manera, si el deute municipal del regne hagués generat pensions per valor d'un milió i mig de sous, i dos terços pertanyessen a censalistes de València, el flux de renda que es canalitzaria a la capital podria assolir el milió de sous. Cap a 1490, tenint en compte que les pensions municipals ascendirien a uns dos milions de sous, seguint aquestes hipòtesis, més d'un milió i quart podria haver afluït a València. Es tracta sobretot d'aproximacions a uns ordes de magnituds, però pot considerar-se que aquesta transferència de rendes podria equivaldre al valor d'un terç del blat que la ciutat consumia anualment $o$ als ingressos que podien reportar un centenar de senyories de dimensions mitjanes com Catarroja o Torrent. El fet de ser el principal centre financer del país reforçava la concentració de riquesa derivada del comerç i contribuïa

\footnotetext{
${ }^{33}$ Pastor 1984.
} 
així a l'atracció de nous habitants que, encara que de manera subordinada i desigual, acabaven participant d'aquest festí rendista. La primacia de ciutat de València sobre la resta de ciutats del regne, només comparable a la de Florència en la Toscana, no seria aliena a una hegemonia política i econòmica que tenia en el mercat censalista una de les seues manifestacions més clares ${ }^{34}$.

Ara bé, com ja s'ha suggerit, al costat de la distribució -o millor, concentració- territorial de les rendes censalistes produïdes pel deute públic, ha de considerar-se la seua circulació entre els diferents sectors socials. D'entrada, qualsevol persona o institució que disposava d'un capital líquid podia invertirlo en el mercat censalista. Això era especialment cert en el crèdit a deutors privats que, ells també, es reclutaven en tots els estrats socials. Una vídua relativament modesta, una tutela, un llaurador o un artesà que disposaven d'uns centenars de sous podien col-locar-los en censals i violaris. Però el finançament del deute públic no era una mena de "rendisme popular". Es necessitaven no centenars, sinó milers de sous per invertir-los en els censals que emetien les ciutats i viles i, sobretot, la capital del regne. D'aquesta manera, no pot sorprendre que els creditors censalistes dels municipis fossen sobretot sectors burgesos i aristocràtics, de manera més accentuada a mesura que s'ascendia en la jerarquia urbana (quadre 2). En la seua cúspide, la ciutat de València, cap a 1370 , un $30 \%$ dels capitals $-\mathrm{i}$ a grans trets, de les pensions- estaven en mans de la noblesa, una part equivalent -un 29\%-pertanyia a ciutadans, és a dir a burgesos decantats cap al rendisme, mentre que els sectors actius com a mercaders i professionals liberals tenien un participació inferior que, en conjunt, se situava en un 20\%. D'aquesta manera, encara que els mercaders podien invertir en censals com a forma de diversificar les seues activitats en un negoci menys lucratiu que el comerç però més segur, que els garantia una certa estabilitat, no hi ha dubte que els grans inversors en el deute públic eren els sectors rendistes, tant nobiliaris com ciutadans. Aquesta extracció social no va fer més que confirmar-se amb l'ampliació del mercat financer. Així, cap a l'any 1400 els ciutadans controlaven un $45 \%$ del deute censalista, la noblesa un $28 \%$ i els sectors burgesos actius -mercaders i professionals liberals- un 18\%. D'aquesta manera, els sectors socials d'orientació rendista -nobles i ciutadans- posseïen quasi les tres quartes parts del deute municipal $i$, en conjunt, si s'afegien els mercaders i professionals liberals, els inversos burgesos i aristocràtics es beneficiaven del $90 \%$ de les rendes censalistes ${ }^{35}$. La situació no era molt diferent un segle després: al llindar del segle XVI,

\footnotetext{
${ }^{34}$ Viciano 2004.

${ }^{35}$ L'extracció socioprofessional dels censalistes de València en 1367-1368 i 1399-1400 ha estat quantificada, a partir dels casos en què es coneix l'ofici dels inversors, per García Marsilla 2002, pp. 261 i 272.
} 
un $75 \%$ del deute estava en mans de nobles i burgesos, als quals s'afegien els eclesiàstics, que amb un 5\% dels censals havien anat augmentant la seua participació en aquest rendisme financer ${ }^{36}$.

En la resta de ciutats i viles reials la situació era similar a la de València, encara que entre la minoria de censalistes locals els burgesos -mercaders, notaris, juristes- estaven lluny del nivell de riquesa $-\mathrm{i}$ de rendes censalistes- que tenien els seus col-legues de la capital, que, de fet, estaven més propers a l'aristocràcia que als notables de les comarques rurals. A més, entre els censalistes de les viles i llocs rurals podien trobar-se artesans i fins i tot pagesos acomodats. A Vila-real, en 1362-1383, la majoria dels censals beneficiaven ciutadans de València i sectors burgesos locals i d'altres viles de la comarca, però un $40 \%$ del capital corresponia a tres censalistes aristocràtics de la capital del regne ${ }^{37}$. També en una població més rural com Vilafamés, els inversors, a part d'un $10 \%$ d'eclesiàstics i un $22 \%$ de nobles, serien sobretot professionals liberals i altres notables de viles properes $^{38}$. Ja al segle XV, cap a 1425 , a Castelló més del $40 \%$ de les pensions beneficiaven ciutadans i burgesos de València, i si se'ls afegien els mercaders i professionals de la mateixa vila, el sector que anomenen burgès controlaria més de la meitat de les rendes. Els eclesiàstics, també gairebé tots de València, percebien un $8 \%$ de les pensions i, finalment, la noblesa -formada per cavallers de la capital del regne- n'ingressava un $28 \%{ }^{39}$. En una altra vila propera com Borriana, en 1449-1456, els censalistes burgesos, pràcticament tots ciutadans, notaris i juristes de la ciutat de València, percebien més de la meitat de les rendes, mentre que els creditors aristocràtics -cavallers i donzells també de la capital-se'n beneficiaven d'un $20 \%{ }^{40}$. En la vila veïna d'Onda, també a mitjan segle XV, la majoria de les pensions eren d'inversors que no formaven part dels estaments privilegiats -entre els quals, a més de burgesos es trobaven artesans i llauradors de les viles dels voltants-, però resulta igualment remarcable que un $20 \%$ de

${ }^{36}$ Ferrero 1987, pp. 61-69. La situació no era gaire diferent a la ciutat de Mallorca, on en 1463, la noblesa ingressava un $30 \%$ de les pensions, els ciutadans un $25 \%$ i els mercaders un $10 \%$, mentre que notaris, juristes i menestrals no arribaven a l'1\% i els eclesiàstics -ací rauria la major diferència- s'acostaven al 15\%, segons càlculs propis amb les dades de Urgell 1997, pp. 698-700. Al Principat, en canvi, la noblesa no tenia una participació remarcable, mentre que l'Església també assolia una major presència que en el cas valencià, segons les contribucions aplegades a Sánchez 2009.

${ }^{37}$ A partir de les dades de Del Pozo 1995, pp. 85-90.

${ }^{38}$ Càlculs efectuats amb les dades de 1372 publicades por Rabassa, Díaz de Rábago 1995, p. 102.

${ }^{39}$ Viciano 1990, pp. 655-657.

${ }^{40}$ En aquest cas, es documenta la presència, entre els censalistes, d'eclesiàstics (un 13\% de les pensions) i d'artesans (8\%). Cf. Viciano 1992, pp. 523-525. 
les rendes pertanyia a aristòcrates de la ciutat de València i una proporció també destacada -gairebé el $15 \%$ - a eclesiàstics ${ }^{41}$. A Cullera un $57 \%$ dels censals documentats en 1390-1500 corresponien a ciutadans rendistes, mercaders $i$ alguns artesans acomodats de València, un $5 \%$ a eclesiàstics i un $37 \%$ a cavallers i nobles de la mateixa ciutat, que segurament representarien un percentatge fins i tot superior dels capitals i les pensions corresponents. A la ciutat d'Alzira, entre 1351 i 1525, la presència de l'Església entre els censalistes augmentava fins a un $15 \%$, i la resta es repartia, gairebé a parts iguals, entre la petita noblesa i l'estament ciutadà ${ }^{42}$. Cap a 1440 , en una població rural propera com era Sueca, els censalistes eclesiàstics ingressaven un $7 \%$ de les pensions i els cavallers entorn d'un $14 \%$, mentre que la majoria es repartien entre mercaders, professionals i artesans de València, d'una banda, i llauradors acomodats de mateixa comunitat local, per una altra ${ }^{43}$. En general, pot afirmar-se que els beneficiaris del deute públic en les viles del regne presentaven una extracció social semblant a la dels censalistes de València, però amb una particularitat: l'hegemonia dels ciutadans i de la baixa noblesa es veia matisada per una major presència que a la capital de mercaders i professionals liberals -en part de les mateixes comarques ruralsi fins i tot d'artesans i pagesos acomodats. Sens dubte, el menor volum dels capitals que demandaven aquests municipis permetia que la sociologia dels inversors en el deute públic s'estengués cap a estrats socials relativament amplis i, en qualsevol cas, més enllà del restringit grup del patriciat urbà.

Pel que fa a la Generalitat, l'altra gran institució generadora de deute públic, de la massa de censals emesos durant la primera meitat del segle $\mathrm{XV}$, concretament entre 1406 i 1464, més del 40\% van ser contractes per creditors pertanyents a la noblesa. Els ciutadans, és a dir, els rendistes burgesos, representaven un $18,5 \%$ dels inversors, seguits pels mercaders, que es van fer amb un $10,2 \%$ del deute. Més enrere quedaven els professionals urbans -notaris i juristes-, amb un 7,2\%, mentre que els eclesiàstics suposaven un 5,8\% dels inversors i els artesans un 5,3\% $\%^{44}$. D'aquesta manera, pot dirse que era en aquesta institució estamental, en la qual la noblesa tenia una representació política molt superior a la que aconseguia a la ciutat de València i a la resta de municipis, on els inversors aristocràtics van aconseguir un major control del deute públic. Però en general, els grans beneficiaris d'aquest

${ }^{41}$ Càlculs propis segons la documentació de 1459 publicada per Fradejas, García 1989, pp. 60-69.

${ }^{42}$ Per a Cullera i Alzira, $c f$. Furió 1993, p. 518.

${ }^{43}$ Percentatges establerts a partir de les pensions pagades en 1438-1446, segons les dades de Mira 1997, p. 91.

${ }^{44}$ López 2005, pp. 379-384. 
entramat financer van ser els sectors burgesos de la capital del país, sobretot els "ciutadans", és a dir, la minoria rendista assimilada al patriciat urbà i, només en segon terme, els mercaders i professionals liberals en actiu. Ara bé, la destacada presència de donzells i cavallers en el deute públic adquireix una significació que va més enllà del seu mer pes quantitatiu, en la mesura que està vinculada a un procés d'abast general com va ser el de la "crisi" -o millor, la insuficiència- de la senyoria com a base econòmica de l'hegemonia social de la noblesa. Al costat de les diverses modalitats de participació en les rendes de la Corona i en l'impost d'Estat -l'anomenada "renda feudal centralitzada"-, l'aristocràcia valenciana va trobar en la inversió en el deute públic una font de renda complementària als ingressos tradicionals de les seues senyories. Però, fins a quin punt? Aquí s'imposa una nova temptativa d'estimació global. En el cas de la ciutat de València, sabem que a l'inici del segle XV la noblesa controlava un $30 \%$ del deute censalista, una presència que, com a mínim, s'havia estabilitzat fins a l'inici del segle XVI. El cas de la resta de ciutats i viles és molt més heterogeni, amb dades parcials tant en termes geogràfics com a cronològics, però en les principals poblacions, ja al segle XV, se situava entorn del $20 \%$ dels censals i les pensions. D'aquesta manera, aplicant aquests percentatges, pot estimar-se que les rendes censalistes que la noblesa obtenia de les inversions en el deute públic superarien el mig milió de sous en 1430 i els tres quarts de milió en $1490^{45}$. Val a dir que aquesta aproximació, efectuada sobre una estimació anterior, té un sentit sobretot indicatiu de les magnituds en què es movia aquest rendisme: mig milió de sous era la renda senyorial que podia obtenir-se de 5.000 vassalls musulmans o de més de 7.000 camperols cristians o, dit d'una altra manera, la renda de mig centenar de senyories de l'horta de València com Catarroja o Torrent. Era, també, el total dels ingressos que produïa el reial patrimoni, és a dir, les rendes dominicals de la Corona. Gràcies a les inversions en el deute censalista, l'estament nobiliari podia ampliar els seus recursos fins a un nivell que, pel cap baix, equivaldria a una hipotètica senyorialització de tot el domini reial.

${ }^{45}$ En 1430 el conjunt de les pensions de la ciutat de València ascendien a uns 500.000 sous, els de les viles del regne poden estimar-se en 1.500.000 i els de la Generalitat en 200.000, de manera que aplicant-hi uns percentatges, respectivament, del 30\%, 20\% y $40 \%$, els ingressos de la noblesa estarien vora els 530.000 sous. En 1490 les pensions globals eren d'uns 700.000 sous per a la capital del regne i s'han estimat en 2 milions per al conjunt de les viles i en uns 400.000 per a la Generalitat, cosa que aplicant-hi els mateixos percentatges, representaria una massa de renda nobiliària d'uns 770.000 sous. 
Quadre 2. Nivell socioprofessional dels creditors censalistes $(\%)^{46}$

\begin{tabular}{|l|l|c|c|c|c|c|c|c|}
\hline & & NOBL. & BURG. $^{*}$ & ARTES. & ECLES. & LLAUR. & $\begin{array}{c}\text { ALTRES/ } \\
\text { DESC. }\end{array}$ & TOTAL \\
\hline $1362-1383$ & Vila-real & 39,2 & 3,9 & 4,9 & & & 52 & $10.200^{\mathrm{a}}$ \\
\hline 1367 & València & 30,3 & 49,5 & 2,1 & 0,2 & 0,4 & 17,5 & $92.200^{\mathrm{b}}$ \\
\hline 1372 & Vilafamés & 21,7 & 10,8 & & 8,6 & & 58,9 & $4.600^{\mathrm{a}}$ \\
\hline 1390 & Cullera & 37,6 & $57,1^{\mathrm{d}}$ & & 5,1 & & & $77^{\mathrm{c}}$ \\
\hline 1399 & València & 27,5 & 62,5 & 4,4 & 1,5 & 0,2 & 3,9 & $440.300^{\mathrm{b}}$ \\
\hline $1406-1464$ & Generalitat & 40,9 & 35,9 & 5,3 & 5,8 & & 12,1 & $10.788 .900^{\mathrm{b}}$ \\
\hline 1412 & València & 38,4 & 44,5 & 6,2 & 4,1 & & 6,8 & $534.600^{\mathrm{a}}$ \\
\hline 1426 & Castelló & 28 & 41 & & 8 & & 23 & $37.600^{\mathrm{a}}$ \\
\hline 1444 & Sueca & 13,2 & 19 & 13,2 & 7 & 32 & 15,6 & $7.600^{\mathrm{a}}$ \\
\hline $1449-1456$ & Borriana & 21,3 & 52,8 & 7,8 & 12,8 & & 5,3 & $41.400^{\mathrm{a}}$ \\
\hline 1459 & Onda & 20,6 & & & & & 79,4 & $31.500^{\mathrm{a}}$ \\
\hline
\end{tabular}

*Inclou ciutadans, mercaders i professions liberals.

${ }^{a}$ Pensions en sous (quantitats arrodonides a la centena). ${ }^{b}$ Capital en sous (quantitats arrodonides a la centena). ${ }^{\mathrm{c}}$ Nombre de contractes. ${ }^{\mathrm{d}}$ Inclou artesans.

\section{ESTRATÈGIES RENDISTES}

Si des d'una perspectiva sistèmica el volum de rendes censalistes que circulava al llarg del territori i entre els diferents estrats socials contribuïa a redistribuir les recaptacions fiscals en un sentit jeràrquic, des del punt de vista de les motivacions dels censalistes, invertir en el deute públic formava part de les seues estratègies econòmiques i socials. En aquest sentit, convé remarcar que, en tots els casos, el que es buscava era una renda, és a dir, un ingrés segur, regular i fix. I honorable. Però no deixa de ser cert que, tot i que el deutor no estava obligat a retornar el capital, els creditors podien recuperar els diners invertits venent la renda a un tercer en l'actiu mercat secundari del deute públic. Això volia dir que, a més de contemplar-se com una font de renda perpètua, el censal també es feia servir com un instrument per apartar temporalment un capital del risc dels afers més especulatius. Invertir en censals, doncs, no era una opció incompatible amb els negocis mercantils o altres dedicacions professionals. Ara bé, si prenem l'exercici municipal de $1412^{47}$,

${ }^{46}$ Font: elaboració pròpia a partir de les dades aportades per Fradejas y García 1989; Furió 1993, 2005; García Marsilla 2002; López Rodríguez 2005; Mira 1997; Del Pozo 1995; Rabassa i Díaz de Rábago 1995; Viciano 1990, 1992.

${ }^{47}$ Furió 2005. 
pot constatar-se el pes determinant a València dels censalistes que, d'entrada, poden assimilar-se a la categoria de rendistes. L'Església i les institucions caritatives ingressaven només un $4 \%$ de les pensions pagades per la ciutat, però la noblesa, és a dir, l'estament rendista per se, se n'enduia més del $38 \%$. L'anomenat "patriciat urbà" arribava al 44\%, però tots aquests inversors no poden identificar-se amb mercaders, canvistes o professionals que buscaven en el censal una mena d'assegurança contra el risc dels altres negocis. La majoria d'aquests censalistes eren ciutadans, un terme que, certament no era unívoc $^{48}$, però que pot associar-se a l'estrat superior que buscava en la renda -de la terra i dels censals- una honorabilitat que els elevava sobre el món mercantil i els acostava a la baixa noblesa ${ }^{49}$. Més encara: pot pensar-se també que una part dels comerciants i professionals que continuaven sent identificats com a tals, en realitat, en culminar una trajectòria d'èxit, ja havien esdevingut rendistes. Era el cas de Joan Amalric, un mercader de València que, en el moment de la seua mort en 1463, ja havia abandonat totalment la mercaderia i vivia de rendes censalistes que majoritàriament provenien de la Generalitat i la ciutat de València ${ }^{50}$. De manera semblant, el jurista Jaume Garcia d'Aguilar, en 1484, també a la fi de la seua vida, gaudia de rendes censalistes que assolien els 16.000 sous anuals, satisfetes sobretot per la capital del regne ${ }^{51}$. Sense arribar a aquests casos extrems, la tendència cap al rendisme i, amb ell, l'ascens d'estament, era un horitzó compartit per tots els nivells del món urbà. La trajectòria de Ramon de Puig-roi, un mercader d'origen barceloní assentat a València a l'inici del segle XV, permet comprovar com, després d'una vida laboral -relativament curta- dedicada al comerç, esdevindria un ciutadà

${ }^{48}$ En la seua accepció estrictament jurídica, el ciutadà de València era el veí que en gaudia dels privilegis i tenia les obligacions corresponents, $\mathrm{i}$ així trobem expressions com "mercader e ciutadà nostre" en boca de les autoritats urbanes (Rubio 2003, p. 168). En l'àmbit polític, els ciutadans era una categoria que identificava els burgesos que podien accedir al govern municipal, diferenciats dels nobles i dels representats dels oficis menestrals (Narbona 1995, 2007). Però com a identificació socioprofessional, tendia a delimitar l'estrat més ric del sector burgès que es decantava cap al rendisme. Ara bé, que els ciutadans puguen considerar-se fonamentalment rendistes -en censals i immobles- no significava que haguessen renunciat totalment a altres activitats econòmiques -tret de les considerades "vils e mecàniques"-, de la mateixa manera que els cavallers no vivien només de les seues senyories ni els llauradors acomodats de les seues terres. Però la possessió de rendes -de censals i de terra- era l'element clau per a conferir als ciutadans l'honorabilitat que els permetia convergir amb la baixa noblesa.

${ }^{49}$ Un bon exemple és un llinatge de ciutadans de València com els Marrades, que a la fi del segle XIV invertien en l'arrendament d'impostos municipals i a l'inici del segle XV, al llindar de la seua promoció a les files de la noblesa, havien optat per esmerçar els seus capitals en el deute públic censalista (Narbona 1992).

${ }^{50}$ Viciano 1991.

${ }^{51}$ Arxiu de Protocols del Patriarca de València, Bartomeu de Carries, 20.440 (agraïm la referència a l'amabilitat de Vicent Escartí). 
rendista allunyat definitivament del tràfic mercantil..$^{52}$ No pot descartar-se, doncs, que la majoria dels capitals que invertien en el deute públic els sectors burgesos s'inserien en estratègies que, sense ser incompatibles amb la recerca de seguretat econòmica, s'orientaven més aviat a la promoció social i la reproducció de l'estatus de ciutadà rendista.

D'altra banda, les pensions dels censals no representaven un simple complement de les rendes senyorials per a un sector de dimensions imprecises, però sens dubte significatiu, de la noblesa valenciana. Resulta ja conegut el cas del donzell Joan Pujades, senyor de Catarroja, que en el moment de la seua mort, en 1429, ingressava uns 15.000 sous anuals de pensions censalistes, provinents sobretot de comunitats rurals, quan les rendes de la seua senyoria no superarien els 10.000 sous $^{53}$. I no es tractava d'un cas excepcional. L'esmentat Jaume Garcia d'Aguilar, un jurista assimilat a la noblesa, segons el seu inventari post mortem de 1484, cobrava cada any uns 16.000 sous censals. Amb un centenar de focs entre vassalls cristians i musulmans, la seua senyoria d'Alaquàs devia reportar una renda feudal que, com a màxim, assoliria la meitat dels ingressos que reportaven les pensions censalistes. Una vegada més, aquestes rendes provenien del deute públic i especialment de la ciutat de València ${ }^{54}$. Amb tota seguretat, tenint en compte la participació destacada dels censalistes aristocràtics en el deute públic dels municipis i de la Generalitat, el conjunt de pensions que anaven a parar a les mans de l'estament nobiliari representaria una enorme massa de diners. El que no pot assegurar-se és que casos com els citats anteriorment fossen representatius d'una situació general.

No hi ha dubte que molts nobles percebien alguna renda censalista, però no devia ser tan habitual que aquests ingressos superassen els que obtenien de les seues senyories. Aquí cal assajar una nova estimació global, amb totes les reserves pertinents però que també pot ser útil per il·luminar la qüestió. A partir del volum total de la població de les senyories laiques i de la renda mitjana que pagava cada foc, pot establir-se una magnitud aproximada de la renda agregada que percebia l'estament aristocràtic. Caldrà distingir, però, entre els vassalls musulmans i els cristians, ja que els primers, en trets generals, estaven sotmesos a una pressió molt superior. Cap a 1430, els vassalls de la noblesa laica ascendien a 17.000 focs, aproximadament la meitat dels quals

\footnotetext{
${ }^{52}$ Cruselles 1995, pp. 130-131. Aquest autor insisteix també en la vocació rendista dels comerciants i de la resta de la "burgesia medieval".

${ }^{53}$ Viciano 1989, pp. 106-114.

${ }^{54}$ L'estimació de les rendes de la senyoria d'Alaquàs s'ha fet a partir de les dades del quadre 2, considerant que en 1488 tenia una població de 96 focs, segons Valldecabres 2002, p. 548.
} 
serien musulmans i l'altra meitat cristians ${ }^{55}$. Pel que fa a la renda mitjana que solien satisfer els camperols musulmans durant el segle XV, en les aljames de les muntanyes que havien preservat millor la seua autonomia, i que sovint havien pertangut al patrimoni reial o a l'alta noblesa, com era el cas de la Serra d'Eslida i de la Vall d'Uixó, la renda mitjana no superava el mig centenar de sous ${ }^{56}$. Ara bé, eren més habituals "taxes de sostracció" majors, entre els 100 i els 150 sous per foc, i fins i tot superiors en les alqueries més petites (quadre 2). En canvi, els vassalls cristians de senyoria -tant laica com eclesiàstica- solien pagar unes rendes per foc molt inferiors. Ací, però, hi havia també situacions diferents, ja que a les terres que havien pertangut al patrimoni reial -com la Pobla de Vallbona o Gandia- i que posteriorment havien estat senyorialitzades la "taxa de sostracció" s'assemblava més aviat a la de les batllies reials. En la mateixa situació es trobaven les terres del Maestrat, que pertanyien -com Sant Mateu- a l'orde de Montesa ${ }^{57}$. Tanmateix, el muntant que s'assolia en senyories d'ordes militars situades en les grans hortes, com Torrent i Sueca, oscillava entre els 60 i els 80 sous $^{58}$. Segurament, tot i que es tracta de vassalls del braç eclesiàstic, aquest nivell de renda seria representatiu també de la majoria dels dominis laics. Així les coses -i a l'espera càlculs més precisos- podria considerar-se que els vassalls musulmans de la noblesa satisfarien, en una estimació prudent, una renda mitjana d'un centenar de sous per foc, i els cristians la meitat. Aplicant aquests mòduls als focs de cristians i musulmans, pot aventurar-se que el conjunt de la renda feudal corresponent a l'aristocràcia laica podia acostar-se a 1,3 milions de sous ${ }^{59}$. En 1488, els vassalls de la noblesa laica havien ascendit a 22.800 focs, que, seguint la mateixa avaluació hipotètica, aportarien una renda global superior a 1,8 milions de sous ${ }^{60}$.

55 Vegeu Viciano (en premsa). Val a dir que la tendència va ser l'increment dels vassalls musulmans, que en 1510 representaven el 60\% de la població senyorial (Viciano 2012, pp. 213 i 243-244).

${ }^{56}$ Calculat a partir del treballs de Guinot 1988; 1992, p. 625.

${ }^{57}$ Calculat a partir de García-Guijarro 1978, pp. 162-163.

${ }^{58}$ Vegeu, per a Torrent, Febrer 1984 (any 1417) i Arxiu del Regne de València, Protocols Notarials, 2.020, 6-VI-1503, i per a Sueca, Furió 1997, p. 517.

${ }^{59}$ Els 17.000 focs es repartirien, seguint les proporcions de 1430 , en uns 8.500 de musulmans, que amb una renda mitjana de 100 sous reportarien uns ingressos globals per als seus senyors d'uns 850.000 sous, mentre que els 8.500 focs cristians, considerant una mitjana de 50 sous, n'aportarien 425.000 més.

${ }^{60}$ Els 22.800 focs es dividirien entre 13.700 de musulmans (60\% dels vassalls) i 9.100 de cristians (40\%), que si se consideren les mateixes rendes mitjanes aplicades en el cas de 1430, reportarien uns ingressos senyorials al voltant d'1.370.000, i de 455.000 sous, respectivament. És raonable pensar que l'estimació de la renda obtinguda dels vassalls cristians s'hagués de reduir en unes desenes de milers de sous, tenint en compte que una part de l'increment d'aquests focs provenia de la senyorialització de possessiones del reial patrimoni, sense que s'hagués produit un augment, almenys immediat, de la renta mitjana per foc, que en el domini del rei no 
Quadre 3. Nivell de les rendes senyorials ${ }^{61}$

\begin{tabular}{|l|l|l|c|c|c|}
\hline & & & RENDES $^{*}$ & FOCS & SOUS/FOC \\
\hline 1412 & Pobla de Vallbona, la & C & 7.400 & $165^{\mathrm{a}}$ & 45 \\
\hline 1412 & Benaguasil & $\mathrm{M}$ & 27.500 & $201^{\mathrm{a}}$ & 137 \\
\hline 1412 & Serra d'Eslida, la & $\mathrm{M}$ & 23.500 & 750 & 31 \\
\hline 1412 & Vall d'Uixó, la & $\mathrm{M}$ & 21.500 & 468 & 46 \\
\hline 1413 & Bunyol & $\mathrm{M}$ & 25.200 & 200 & 126 \\
\hline 1417 & Torrent & $\mathrm{C}$ & 10.000 & $152^{\mathrm{c}}$ & 65 \\
\hline 1420 & Gandia & $\mathrm{C}$ & 11.500 & $363^{\mathrm{b}}$ & 31 \\
\hline 1430 & Sant Mateu & $\mathrm{C}$ & 15.800 & 465 & 34 \\
\hline 1431 & Faldeta & $\mathrm{M}$ & 2.500 & 13 & 192 \\
\hline 1439 & Alberic i Benifaraig & $\mathrm{M}$ & 16.500 & $222^{\mathrm{b}}$ & 74 \\
\hline 1445 & Xiva i Vilamarxant & $\mathrm{M}$ & 24.000 & $276^{\mathrm{b}}$ & 87 \\
\hline 1449 & Torís & $\mathrm{M}$ & 6.000 & 42 & 142 \\
\hline 1466 & Anna & $\mathrm{M}$ & 10.000 & $60^{\mathrm{b}}$ & 167 \\
\hline 1467 & Picassent & $\mathrm{M}$ & 15.000 & $109^{\mathrm{b}}$ & 137 \\
\hline 1469 & Vilallonga & $\mathrm{M}$ & 22.000 & $180^{\mathrm{b}}$ & 122 \\
\hline 1471 & Sueca & $\mathrm{C}$ & 14.700 & $183^{\mathrm{d}}$ & 80 \\
\hline 1471 & Xiva & $\mathrm{M}$ & 15.000 & $165^{\mathrm{b}}$ & 91 \\
\hline 1472 & Sallent & $\mathrm{M}$ & 5.500 & $33^{\mathrm{b}}$ & 167 \\
\hline 1474 & Genovés, el & $\mathrm{M}$ & 5.500 & $39^{\mathrm{b}}$ & 141 \\
\hline 1478 & Valldigna, la & $\mathrm{M}$ & 65.000 & $660^{\mathrm{e}}$ & 98 \\
\hline 1480 & Terrateig & $\mathrm{M}$ & 3.200 & $18^{\mathrm{b}}$ & 178 \\
\hline 1492 & Llombai & $\mathrm{M}$ & 22.100 & 143 & 154 \\
\hline 1503 & Torrent & $\mathrm{M}$ & $7.000^{\mathrm{f}}$ & $115^{\mathrm{e}}$ & 78 \\
\hline 1509 & Bellreguard & & & & 106 \\
\hline & & & & \\
\hline
\end{tabular}

*En sous, quantitats arrodonides a la centena

C: vassalls cristians $\mathrm{M}$ : vassalls musulmans

${ }^{\mathrm{a}} 1418{ }^{\mathrm{b}} 1488{ }^{\mathrm{c}} 1415{ }^{\mathrm{d}} 1453{ }^{\text {e }} 1510{ }^{\mathrm{f}}$ ARV, Protocols Notarials, 2.020, 6-VI-1503.

Si es comparen aquestes aproximacions al volum de la renda feudal amb les corresponents al total de pensions censalistes satisfetes per les institucions públiques a la noblesa -que hem estimat, amb totes les reserves, en vora mig milió de sous cap a 1430 i entorn de tres quarts de milió cap a

arribava a la meitat de l'habitual en les antigues senyories nobiliàries. Però, tot i amb això, pot admetre's que la renda global de l'aristocràcia s'acostaria a 1,8 milions de sous.

${ }^{61}$ Font: elaboració pròpia a partir de les dades aportades per Febrer 2006; Furió 1997; García-Guijarro 1978, Guinot 1988, 1992; López Rodríguez 2005; Meyerson 1994; Pastor 1992; Ruzafa 1993; Valldecabres 2002. 
1488- pot avançar-se la hipòtesi que les rendes tradicionals de les senyories duplicarien amb escreix el pes del nou rendisme censalista. No cal dir que aquestes aproximacions són grolleres i que en el cas dels ingressos censalistes de la noblesa es tracta d'una estimació a partir d'una altra estimació prèvia (el volum total de pensions). Tot $\mathrm{i}$ amb això, constitueixen un indici raonable del fet que les rendes censalistes i les estrictament senyorials se situaven en un ordre de magnitud comparable, però que malgrat la tendència ascendent de les primeres, la base econòmica de la noblesa, prenent en conjunt tot l'estament aristocràtic, continuava centrada en els ingressos de les senyories. Ara bé, dins de la noblesa hi havia estrats molt diferents. Una part creixent dels membres de l'estament militar, els que no disposaven de senyories, tenien en el censal la seua principal font de renda ${ }^{62}$. D'altra banda, la noblesa terratinent tampoc no es manifestava com un bloc monolític respecte a la qüestió censalista, sinó que es detecten comportaments que diferenciaven els alts barons de les files de la cavalleria. Els primers, amb ingressos senyorials més voluminosos, se situarien preferentment en el costat dels deutors, mentre que els segons, amb unes bases territorials més febles, estarien entre els creditors censalistes.

A mitjan segle XVI, el cronista Martí de Viciana considerava que els ingressos censalistes eren una font de renda habitual i honorable de la noblesa valenciana: En este reino de Valencia ay señores y varones que biven con sus estados, y otros cavalleros con rentas de censales, y otros donzeles y generosos con ricos heredamientos y labranças ${ }^{63}$. Segons el cronista, seria l'estrat mitjà de l'aristocràcia, els cavallers, el que s'havia decantat més clarament pel rendisme censalista. Encara que es tracta d'una descripció de traços gruixuts, aquesta apreciació de Viciana no deixa de ser coherent amb les divisions que escindien al braç militar en els debats polítics parlamentaris a l'entorn del problema censalista. Encara que no existia, una representació pròpia de la baixa noblesa, durant el segle XV el sector mitjà, compost sobretot per cavallers, en les qüestions relatives l'execució dels deutes censalistes es va posar al costat de les poblacions reials, que representaven els interessos dels creditors burgesos, contra la pretensió dels barons d'entrebancar i dilatar els procediments $^{64}$.

Pot establir-se així que l'orientació cap als censals es donava, en primer lloc, entre els fadristerns i burgesos ennoblits sense vassalls. Però també en l'estrat cavalleresc, que fonamentalment buscava una font d'ingressos se-

\footnotetext{
${ }^{62}$ El nombre de localitats pertanyents a la noblesa -i una senyoria podia incloure'n més d'una- era de 225 en 1430 i de 244 en 1488, quan el nombre de contribuents del braç militar passà de 307 a 541 individus en aquests anys, segons López 2005, pp. 84-86 i 100-101.

${ }^{63}$ Viciana 2013, p. 397.

${ }^{64}$ López 2005, pp. 335-338.
} 
gura i regular -i per descomptat honorable- per reforçar les rendes dels seus dominis, sovint estancades i insuficients. Al mateix temps, disposar d'una font de renda alternativa a la de la senyoria permetia salvaguardar la integritat del domini territorial a l'hora de dividir les herències o casar les filles, ja que els dots i les donacions als fadristerns constaven sobretot de censals. Ara bé, si el perfil social dels censalistes aristocràtics i les seues motivacions poden fer-se intel-ligibles, queda per precisar d'on procedien els capitals que els cavallers invertien en el deute públic. Una cosa està clara: aquestes grans sumes de diners líquids no podien procedir dels seus modests dominis territorials. Les rendes de les senyories valencianes, fonamentalment agràries, a penes podien sostenir el nivell de vida aristocràtic d'aquesta baixa noblesa i difícilment permetien acumular quantitats en moneda que poguessen transformar-se, de cop i volta, en capitals censalistes. Els diners calia buscar-los en un altre costat, en el gran comerç i l'impost. D'una banda, les fortunes obtingudes pels mercaders en el comerç, una activitat no del tot honorable malgrat els esforços legitimadores de moralistes com Francesc Eiximenis, solien blanquejar-se mitjançant la seua conversió en rendes censalistes. Els mercaders d'èxit acabaven la seua trajectòria personal convertint-se en rendistes, en "ciutadans" que s'assimilaven al patriciat urbà, on confluïen amb cavallers, donzells i generosos. Aquesta alta burgesia enllaçava matrimonialment amb els llinatges de la baixa noblesa i fins i tot podia incorporar-se directament a l'aristocràcia per ennobliment. D'aquesta manera, la permeabilitat entre la burgesia rendista i la baixa noblesa permetia a l'estrat cavalleresc, de vell o nou encuny, l'adquisició de capitals líquids o, sovint, d'un patrimoni censalista ja constituït a través d'herències i dots. L'altra via era el servei a la Corona, sobretot en la gestió de la fiscalitat i de la hisenda. En aquest cas accedir als diners no excloïa la confusió entre la gestió pública i el negoci privat, com es posava habitualment de relleu quan els funcionaris reials havien de rendir comptes de la seua administració. En aquest sentit, pot destacar-se que Joan Pujades, el donzell titular de Catarroja i propietari d'un sòlid patrimoni censalista, era germà del cavaller Mateu Pujades, tresorer d'Alfons el Magnànim al regne de Nàpols ${ }^{65}$. En qualsevol cas, cal destacar que l'enllaç amb famílies de mercaders enriquits i el servei en la burocràcia de l'Estat constituïen pràctiques socials dels llinatges cavallerescos que no eren habituals en l'alta noblesa, una circumstància que seria coherent amb la diferent posició que adoptaven els dos estrats aristocràtics davant la qüestió censalista: els cavallers actuant com a creditors i els barons com a deutors.

${ }^{65}$ Val a dir que Mateu Pujades acabaria heretant la senyoria de Catarroja i que, en morir, li fou embargada, amb tots els seus béns, a causa de les irregularitats de la seua gestió com a tresorer. $C f$. Viciano 1989, pp. 41-42. 


\section{RENDA CENSALISTA I TRANSFORMACIONS SOCIALS}

L'enorme massa de renda censalista que produïa el deute públic a la fi de l'edat mitjana va afavorir processos generals de transformació social, com va ser, en primer lloc, l'aristocratització de les grans famílies ciutadanes per ennobliment i enllaç matrimonial amb els antics llinatges cavallerescos. La "transsubstanciació" dels guanys obtinguts en els negocis mercantils en rendes honorables constituïa una de les bases materials -potser la més important-d'aquest procés de reestructuració que afectava els nivells superiors de la societat feudal. D'altra banda, la transferència de recursos, sota la forma de pensions, des del món rural i les ciutats i viles del regne cap a València contribuïa a reforçar-ne la capitalitat, ara com a centre d'un mercat financer que s'estenia a tot el territori valencià. De fet, no sembla que hi hagués cap altra activitat econòmica -industrial o mercantil- en què s'hagués assolit un nivell d'integració semblant, amb una hegemonia tan marcada de la ciutat de València sobre el conjunt del seu regne. No pot descartar-se que els capitals que els censalistes urbans tenien col-locats en el deute de molts llocs i viles fos comparable, si no superior, al volum dels que s'hi invertien en negocis comercials. D'aquesta manera, la influència de la ciutat sobre el seu entorn rural no es limitaria a una demanda que, certament, estimulava la innovació i la comercialització agràries, sinó que tindria també uns efectes descapitzalitzadors, atès l'impacte del drenatge de riquesa que suposava la consolidació i eternització del deute públic censalista. La integració de mercat del crèdit públic contribuïa alhora a la dominació de la ciutat -en realitat del seu estrat oligàrquic- sobre el conjunt del país ${ }^{66}$.

Si per a l'estrat superior de l'estament ciutadà les inversions en el deute públic eren un instrument de promoció social, per a la noblesa representaven, en primer lloc, una font d'ingressos que complementava les rendes de les seues senyories i fins i tot podia arribar a substituir-les, com en el cas dels fadristerns que no participaven en l'herència dels dominis familiars. Tenint en compte que, en el primer terç del segle XV, el volum total de les pensions públiques ingressades per la noblesa se situaria al voltant del mig milió se sous, pot valorar-se l'impacte que tindria aquesta nova font de renda en l'atenuació de la conflictivitat nobiliària que, en altres llocs, anava unida a la crisi de les rendes senyorials. D'entrada, la massa de renda censalista en mans de l'aristocràcia assolia un abast equivalent al dels ingressos de

\footnotetext{
${ }^{66}$ Aquesta acumulació de renda en mans del patriciat de València generava, òbviament, una demanda de productes sumptuaris -des de la pintura a la construcció- que estimulava certes activitats econòmiques, però pot pensar-se que això no compensaria l'impacte negatiu del deute públic, a través de la fiscalitat municipal, sobre la majoria de la població urbana i rural.
} 
tot el patrimoni reial del País Valencià, cosa que devia contribuir a afluixar les pressions senyorialitzadores sobre aquestes terres i, per tant, a rebaixar els conflictes amb la Corona i amb el braç reial, encapçalat per la ciutat de València. El fet que les pensions públiques equivalien, en un altre ordre de comparacions, a la renda d'una cinquantena de senyories mitjanes de vassalls cristians, quan els membres de l'estament militar ascendien a uns tres-cents individus i posseïen dos centenars de poblacions, permet pensar que el censal públic ampliava virtualment però de manera significativa els dominis aristocràtics. Expressat en focs, el mig milió de pensions equivaldria a les rendes pagades per més de 7.000 vassalls cristians o 5.000 de musulmans, cosa que suposaria un hipotètic i notable increment sobre dels 17.000 focs que pertanyien en 1430 a l'estament nobiliari. Dit d'una altra manera, el deute censalista permetia a l'aristocràcia valenciana, entesa com un bloc estamental, compensar l'estancament o la caiguda de les rendes senyorials mitigant, així, la conflictivitat amb la Corona i les ciutats reials, d'una banda, i la competència interna entre els llinatges o fins i tot dins de les mateixes famílies. En aquest sentit, contribuïa a l'estabilitat social i política en una època de dificultats, ja que el pes de les tensions es desviava cap als municipis endeutats, que havien de fer front a una sempre latent conflictivitat fiscal. En qualsevol cas, els nobles no s'enfrontaven a les ciutats i viles endeutades com a senyors, sinó com a part d'un entramat financer que els feia solidaris dels censalistes burgesos establerts sobretot a València. Aquest interès compartit, i l'enllaç amb els sectors superiors del patriciat urbà, tendia a accentuar la divisió interna de la noblesa, definint un estrat mitjà de cavallers que, a diferència dels grans barons, es beneficiava de la maquinària censalista i estava disposat a fer costat als prohoms burgesos en les polítiques que n'asseguraven el funcionament i l'estabilitat.

La Corona podia veure's afavorida per la desactivació de les turbulències nobiliàries, però el rendisme censalista, tal com estava organitzat, erosionava un instrument de domesticació de la noblesa com era el control i distribució de l'impost, de l'anomenada "renda feudal centralitzada". Sens dubte, la monarquia assignava pensions i pagava retribucions als seus servidors aristocràtics com a tot arreu, però la gran massa de rendes censalistes provinents del deute públic no depenia de la gràcia reial, sinó que els cavallers se'n beneficiaven com a inversors privats. En aquest aspecte, els nobles gaudien d'una certa independència respecte a la Corona, però la influència del poder reial es reforçava indirectament, com a garant últim del funcionament del mercat financer teixit al voltant del deute censalista. El flux regular de les pensions des de les hisendes municipals, començant per la capital del regne, fins a les bosses dels censalistes depenia de l'estabilitat política i, vingut el cas, de la capacitat de coerció per a fer efectius els pagaments. I l'única instància 
capaç de garantir-ho era el poder reial. La intervenció de la Corona podia arbitrar els conflictes entre els municipis deutors i els creditors censalistes -inclosos els aristocràtics-, a fi de promoure acords que permetessen alleugerir la càrrega del deute a canvi del pagament de bona part de les pensions. La contrapartida per a les ciutats i viles que havien fet fallida era un veritable rescat financer amb fons reials, que tenia com a contrapartida, com succeí a Borriana a mitjan segle XV i a Castelló a la fi de la centúria, el control de la hisenda local per part d'oficials enviats per la Corona. Aquests acords per a efectuar els quitaments es basaven, no sols en la pèrdua de l'autonomia municipal, sinó en una reducció dràstica de la despesa i, sobretot, en un increment asfixiant de la pressió fiscal directa a través de la peita. L'enorme pressió del deute censalista, doncs, afeblia la posició econòmica i política de les ciutats i viles -sobretot del braç reial- i les abocava a una dependència redoblada de la Corona, que fins i tot podia intervenir autoritàriament per modificar els sistemes electorals, com succeí amb la imposició de la insaculació, per limitar els efectes desestabilitzadors de lluites de faccions oligàrquiques i disciplinar la política local sota la seua hegemonia. El poder reial, doncs, no sols es beneficiava directament del l'entramat censalista com a mecanisme per agilitzar la recaptació dels imposts i d'ampliar així les estructures estatals, sinó que podia aprofitar els efectes col-laterals del deute públic per reafirmar el seu domini sobre els municipis i la seua capacitat d'arbitratge polític per assegurar l'estabilitat d'aquest mercat financer.

Per als municipis, en un primer moment, el censal, amb un interès moderat i sense la pressió de l'amortització, va suposar un alleujament respecte a les modalitats de crèdit a curt termini anteriors. Podria pensarse, en una perspectiva diguem-ne weberiana, que el deute públic va afavorir el desenvolupament d'una racionalitat burocràtica, que anava des de la implantació d'un veritable sistema fiscal fins al perfeccionament de la gestió de les finances públiques. Ara bé, és difícil pensar que, per ell mateix, el desenvolupament burocràtic podria qüestionar els aspectes negatius del deute públic, si es té en compte que la funció bàsica de la maquinària estatal era transferir rendes des de les masses contribuents fins les elits polítiques i financeres, a través d'una creixent pressió fiscal que no sols ofegaria les viles rurals del regne, sinó que també pesava sobre la majoria dels habitants de la mateixa ciutat de València ${ }^{67}$. De fet, ja a l'inici del segle XVI, la qüestió del

${ }^{67} \mathrm{Ja}$ autors com Blockmans (1987) assenyalaven que el sistema fiscal i l'impacte del deute públic reforçaven les desigualtats socials. Més recentment, historiadors de l'economia com Alfani i Ryckbosch (2016) han quantificat l'impacte negatiu de la desigualtat econòmica en els processos de desenvolupament en les societats preindustrials, i com aquesta desigualtat es veia alimentada per la transferència de rendes a les elits socials i polítiques a través d'una fiscalitat regressiva, de la despesa militar i del deute públic. No es tracta, doncs, de fer un judici moral 
deute censalista i de l'impost municipal, al costat de l'ampliació social de la representativitat política, centraria les reivindicacions dels agermanats. Els radicals que volien suprimir les cises i anul-lar els censals carregats feia ja vint-i-cinc anys ${ }^{68}$ actuaven moguts per una mena de "narrativa pessimista" del deute públic. Sens dubte no podien tenir perspectiva històrica per copsar l'abast dels reajustaments socials que eren alimentats pel rendisme censalista, però sí que sabien quin era el seu cost i qui el pagava.

\section{BIBLIOGRAFIA CITADA}

Alfani, Guido; Ryckbosch, Wouter (2016), Growing Apart in Early Modern Europe? A Comparison of Inequality Trends in Italy and the Low Countries, 1500-1800, "Explorations in Economic History" 62, pp. 143-153.

Belenguer, Ernest (1976), València en la crisi del segle XV, Barcelona, Edicions 62.

Blockmans, Wim (1987), Finances publiques et inégalité sociale dans les Pays-Bas aux XIV ${ }^{e}-X V I^{e}$ siècles, en Genêt, Jean-Philippe; Le Mené, Michel (eds.), Genèse de l'État moderne. Prélèvement et redistribution, París, CNRS, pp. 77-90.

Boone, Marc; Davids, Karel; Janssens, Paul (2003), Urban Public Debts, Urban Government and the Market for Annuities in Western Europe (1 $14^{\text {th }}-18^{\text {th }}$ Centuries), Turnhout, Brepols.

Cruselles, Enrique (1995), El corn de l'abundància, en Narbona, Rafael, et al., L'univers dels prohoms (Perfils a la València baix-medieval), València, Tres i Quatre, pp. 95-135.

Febrer, Manuel V. (1984), L'arrendament dels drets i rendes de l'encomanda de Torrent l'any 1417, "Torrens" 3, pp. 269-271.

Febrer, Manuel V. (2006), Les aljames mudèjars valencianes en el segle XV, València, Publicacions de la Universitat de València.

Ferrero, Remedios (1987), La hacienda municipal de Valencia durante el reinado de Carlos $V$, València, Ajuntament de València.

Fradejas, F. Carlos; García, Pilar (1989), El régimen municipal de Onda a mediados del siglo XV, "Butlletí del Centre d'Estudis d'Onda" 2, pp. 9-87.

d'una suposada "traïció de la burgesia" o d'un "parasitisme rendista", sinó de valorar els efectes econòmics i socials de l'extracció de recursos fiscals en benefici d'una minoria dominant.

${ }^{68}$ Davant l'aprensió dels dirigents moderats com el mercader Joan Caro, censalista ell mateix de la ciutat. Vegeu, Vallés 1995, pp. 271-273. 
Furió, Antoni (1993), Crédito y endeudamiento: el censal en la sociedad rural valenciana (siglos XIV-XV), dins Sarasa, Esteban; Serrrano, Eliseo (eds.), Señorío y feudalismo en la Península Ibérica (siglos XII-XIX), Saragossa, Gobierno de Aragón, vol. I, pp. 501-534.

Furió, Antoni (1995), Història del País Valencià, València, Institució Valenciana d'Estudis i Investigació.

Furió, Antoni (1997), Estructures fiscals, pressió tributària i reproducció econòmica al País Valencià en la baixa Edat Mitjana, en Sánchez, Manuel; Furió, Antoni (eds.), Corona, municipis i fiscalitat a la baixa Edat Mitjana, Lleida, Institut d'Estudis Ilerdencs, pp. 495-525.

Furió, Antoni (1999), Deuda pública e intereses privados. Finanzas y fiscalidad municipales en la Corona de Aragón, "Edad Media. Revista de Historia" 2, pp. 35-79.

Furió, Antoni (2002), La dette dans les dépenses municipales, en Menjot, Denis; Sánchez Martínez, Manuel (coords.), La fiscalité des villes au Moyen Âge (Occident Meditérranéen). La redistribution de l'impôt, Toulouse, Privat, pp. 321-350.

Furió, Antoni (2005), Impôt et dette publique. Système fiscal et stratégies financières à Valence à la fin du Moyen Âge, en Menjot, Denis; Rigaudière, Albert; Sánchez Martínez, Manuel (eds.), L’impôt dans les villes de l'Occident méditerranéen, $X I I^{e}{ }^{e}-X V^{e}$ siècle, París, Comité pour l'histoire économique et financière de la France, pp. 39-62.

Furió, Antoni (2018), El deute públic municipal al regne de València en la baixa edat mitjana. Un assaig de quantificació, en Igual, David; Navarro, Germán (coords.), El País Valenciano en la Baja Edad Media. Estudios dedicados al profesor Paulino Iradiel, València, Publicacions de la Universitat de València, pp. 71-136.

Furió Antoni; Garcia-Oliver, Ferran (1985), La economía municipal de Alzira a fines del siglo XIV según un libro de cuentas de 1380-1381, "En la España Medieval" 7,pp. 1611-1634.

García-Guijarro, Luis (1978), Datos para el estudio de la renta feudal maestral de la orden de Montesa en el siglo XV, València, Institución Alfonso el Magnánimo.

Garcia-Oliver, Ferran (1997), El censal al senyoriu. Valldigna (1393-1530), "Revista d'Història Medieval" 8, pp. 153-173.

García Marsilla, Juan V. (2002), Vivir a crédito en la Valencia medieval. De los orígenes del sistema censal al endeudamiento del municipio, València, Publicacions de la Universitat de València.

Guinot, Enric (1988), Demografia medieval del nord del País Valencià, en Estudis sobre la població del País Valencià, València, Edicions 
Alfons el Magnànim de l'IVEI - Institut d'Estudis Juan Gil Albert Seminari d'Estudis sobre la població del País Valencià, pp. 229-249. Guinot, Enric (1992), El patrimoni reial al País Valencià a inicis del segle XV, "Anuario de Estudios Medievales" 22, pp. 581-639.

López Rodríguez, Carlos (1994), La Tesorería General de Alfonso V el Magnánimo y la Bailía General del Reino de Valencia, "Hispania" 187, pp. 421-446.

López Rodríguez, Carlos (2005), Nobleza y poder político en el reino de Valencia (1416-1446), València, Publicacions de la Universitat de València.

Menjot, Denis; Rigaudière, Albert; Sánchez Martínez, Manuel (eds.) (2005), L'impôt dans les villes de l'Occident méditerranéen, $X I I I^{e}-X V^{e}$ siècle, París, Comité pour l'histoire économique et financière de la France.

Meyerson, Mark D. (1994), Els musulmans de València en l'època de Ferran i Isabel. Entre la coexistència i la croada, València, Institució Valenciana d'Estudis i Investigació (ed. or. 1991).

Mira Jódar, Antonio J. (1997), Las finanzas del municipio. Gestión económica y poder local. Sueca ( $s$. XV-XVI), València, Diputació de València.

Mira Jódar, Antonio J. (2005), Entre la renta y el impuesto. Fiscalidad, finanzas y crecimiento económico en las villas reales del sur valenciano (siglos $X I V$-XVI), València, Publicacions de la Universitat de València.

Muñoz, Rosa (1987), Orígenes de la Generalidad Valenciana, València, Generalitat Valenciana.

Narbona, Rafael (1992), Finanzas municipales i patriciado urbano: Valencia a finales del Trescientos, "Anuario de Estudios Medievales" 22, pp. 485-512.

Narbona, Rafael (1995), Valencia, municipio medieval. Poder político y luchas ciudadanas (1239-1418), València, Ajuntament de València, 1995.

Narbona, Rafael (2007), Algunas reflexiones sobre la participación vecinal en el gobierno de las ciudades de la Corona de Aragón (ss. XII-XV), "Res publica" 17, pp. 113-150.

Olaso, Vicent (1987), L'endeutament censal a la vila de Gandia durant la Baixa Edat Mitjana, "Ullal" 11, pp. 51-64;

Pastor Zapata, José L. (1984), Censales y propiedad feudal. El Real de Gandía: 1407-1550, "En la España Medieval” 5, pp. 735-766.

Pastor Zapata, José L. (1992), Gandia en la Baixa Edat Mitjana: la vila i el senyoriu dels Borja, Gandia, CEIC Alfons el Vell.

Pozo, José A. del (1995), Prohoms i camperols. Espai agrari i poder local a Vila-real (1362-1386), Vila-real, Ajuntament de Vila-real. 
Rabassa, Carles; Díaz de Rábago, Carmen (1995), Documents per a la historia de Vilafamés, València, Generalitat Valenciana.

Rubio Vela, Agustín (2003), Epistolari de la València medieval, València, Institut Interuniversitari de Filologia Valenciana - Barcelona, Abadia de Montserrat.

Ruzafa, Manuel (1993), Señores cristianos y campesinos mudéjares en el País Valenciano (siglo XV), en Sarasa, Esteban; Serrano, Eliseo (eds.), Señorío y feudalismo en la península Ibérica (ss. XII-XIX), Saragossa, Intitución "Fernando el Católico", vol. III, pp. 423-433.

Sánchez Martínez, Manuel (ed.) (1999), Fiscalidad real y finanzas urbanas en la Cataluña medieval, Barcelona, CSIC.

Sánchez Martínez, Manuel (ed.) (2009), La deuda pública en la Cataluña bajomedieval, Barcelona, CSIC.

Sánchez Martínez, Manuel; Menjot, Denis (coords.) (1996-2005), La fiscalité des villes au Moyen Âge (Occident Meditérranéen), 4 vols, Toulouse, Privat.

Sánchez Martínez, Manuel; Menjot, Denis (eds.) (2006), Fiscalidad de Estado y fiscalidad municipal en los reinos hispánicos medievales, Madrid, Casa de Velázquez.

Urgell, Ricard (1997), Dinàmica del deute públic a la universitat de Mallorca al segle XV, en Sánchez, Manuel; Furió, Antoni (eds.), Corona, municipis $i$ fiscalitat a la baixa Edat Mitjana, Lleida, Institut d'Estudis Ilerdencs, pp. 675-701.

Valldecabres, Rafael (ed.) (2002), El cens de 1510. Relació de focs valencians ordenada per les corts de Montsó, València, Publicacions de la Universitat de València.

Vallés, Vicent (1995), Vida pública i mort de Vicent Caro, mercader, en Rafael Narbona, et al., L'univers dels prohoms (perfils a la València baixmedieval), València, Tres i Quatre, pp. 257-291.

Viciana, Martí de (2013), Libro segundo de la Crónica de la ínclita y coronada ciudad de Valencia y de su reino, ed. Joan Iborra, València, Publicacions de la Universitat de València (ed. or. 1564).

Viciano, Pau (1989), Catarroja: una senyoria de l'Horta de València en l'època tardomedieval, Catarroja, Ajuntament.

Viciano, Pau (1990), Ingrés i despesa d'una vila valenciana del Quatrecents. Les finances municipals de Castelló de la Plana (14261427), "Boletín de la Sociedad Castellonense de Cultura" 66, pp. 635-664.

Viciano, Pau (1991), L'estratègia rendista del patriciat valencià: el censal $i$ la terra en les inversions d'un mercader del segle XV "Afers" 11-12, pp. 127-136 (reeditat en Viciano 2007, pp. 191-201). 
Viciano, Pau (1992), Fiscalitat local $i$ deute públic al País Valencià. $L$ 'administració de la vila de Borriana a mitjan segle $X V$, "Anuario de Estudios Medievales" 22, pp. 513-533.

Viciano, Pau (2004), Marché du crédit et structuration de l'espace rural. Le Pays Valencien au XVe siècle, "Histoire et Sociétés Rurales" 21, pp. 11-38 (reeditat en Viciano 2007, pp. 119-142).

Viciano, Pau (2007), Senyors, camperols i mercaders. El món rural valencià al segle $X V$, Catarroja - Barcelona, Editorial Afers.

Viciano, Pau (2008), Regir la cosa pública. Prohoms i poder local a la vila de Castelló (segles XIV-XV), València, Publicacions de la Universitat de València.

Viciano, Pau (2012), Els peus que calciguen la terra. Els llauradors del País Valencià a la fi de l'edat mitjana, València, Publicacions de la Universitat de València.

Viciano, Pau (en premsa), Crisi o redistribució demogràfica? La població del braç nobiliari del regne de València al segle XV, en La crisi baixmedieval a la Corona d'Aragó (1350-1450), Palma de Mallorca, Illa edicions.

Zuijderduijn, C. Jaco (2009), Medieval Capital Markets. Markets for Renten, State Formation and Private Investment in Holland (1300-1550), Leiden, Brill.

Fecha de recepción del artículo: octubre 2015

Fecha de aceptación y versión final: diciembre 2016 